\title{
Posturo-kinetic organisation during the early phase of voluntary upper limb movement. 1 Normal subjects
}

\author{
M ZATTARA, S BOUISSET
}

From the Laboratoire de Physiologie du Mouvement, Université Paris-Sud, Orsay, France

SUMMARY The nature and organisation of anticipatory postural adjustments (APA) associated with the early phase of a voluntary upper limb movement were studied. Upper limb elevations, performed at maximal velocity, were studied according to three conditions: bilateral flexions (BF) and unilateral flexions without and with an additional inertia (respectively OUF and IUF).

Activities of the anterior part of the deltoid (DA) and of main muscles of the lower limbs, pelvis, trunk and scapular girdle were recorded by surface electromyography. Miniature-accelerometers enabled the recording of the tangential acceleration of the arm at wrist level (Aw) and the anteroposterior accelerations of various body links. Systematic investigations allow a precise description of the segmental phenomena which precede the onset of the voluntary movement. Before the activation of the anterior deltoid, a sequence of EMG modifications occurred in muscles of lower limbs, pelvis and trunk. The onset of Aw was preceded by anticipatory local accelerations of all the body links. Anticipatory EMG activities and local accelerations were organised according to patterns which were specific to the forthcoming voluntary movement. By comparing anticipatory EMG activities with anticipatory local accelerations, the nature of anticipatory postural movements can be determined. They appear to counteract the disturbing effects of the forthcoming voluntary movement. Because of their reproducibility and specificity, the anticipatory postural movements can be considered as preprogrammed. Postural adjustments and voluntary movement appear to be parts of the same motor program. Anticipatory postural movements should result from muscular functional synergies selected from a pre-evaluation of the perturbative aspects of the forthcoming movement.

The existence of postural adjustments related to voluntary movement has been known since Babinski's observations ${ }^{1}$ and many kinesiological studies have described postural muscular activities associated with simple or complex voluntary movement (see for example Basmajian and De Luca ${ }^{2}$ ).

In 1943 , Hess $^{3}$ put forward the hypothesis according to which the execution of a voluntary movement is influenced by initial posture and includes a postural component besides a purely motor one: he suggested that, during the movement, the postural component counteracts the perturbation to postural equilibrium associated with voluntary movement. Nevertheless, it was the Russian School which first set out the problem in terms of the Theory of Systems. Enlarging on

Address for reprint requests: M Zattara, Laboratoire de Physiologie du Mouvement, Université Paris-Sud, 91405 Orsay, France.

Received 1 June 1987 and in revised form 2 December 1987. Accepted 7 December 1987
Bernstein's hypothesis, ${ }^{4}$ Gelfand $e t a l^{5}$ postulated the existence of functional synergies: "A synergy is a fixed and reproducible interaction of joints or groups of joints, organised and controlled by the central nervous system for effective solution of a specific motor problem". For these authors, the central motor program concerns not only the voluntary mobilised limb(s) but also the other body parts, in particular those which are involved in the postural activity. In studying the programming of voluntary movements, it is well known that the preparatory period holds a special interest. Thus, Belenkii et $a l^{6}$ have shown in erect Man that postural electromyographic activities happen prior to (and during) a voluntary movement of the upper limb and are specific to it; these authors have stressed the idea according to which the aim of postural activities should be to maintain balance with a minimum of energy expenditure.

Since this pioneering study, anticipatory postural activities have been observed in Man in more or less similar situations ${ }^{7-13}$ and in quadrupeds. ${ }^{14-16}$ 
Moreover, clinical experiments have shown that anticipatory postural activities were either reduced or abnormal in pathologic subjects with motor impairments. ${ }^{17-20}$ These results were in agreement with others from animal investigations which have shown that nervous structures involved in extra-pyramidal motricity were associated to anticipatory postural activities. ${ }^{14,21,22}$ Thus, studying relations between voluntary and associated postural activities appears to be a relevant method for elucidating coordination between pyramidal and extra-pyramidal motricity. Nevertheless, programming and biochemical involvement of anticipatory motor activity are far from being wholly elucidated.

The aim of the present paper is to give a precise description of the segmental phenomena which precede the onset of the intentional movement. It seems in particular necessary to determine the biomechanical nature of anticipatory postural adjustments corresponding to the anticipatory muscular activities. On the basis of previous research ${ }^{23-25}$ it is assumed that the voluntary movement constitutes a perturbation of the body balance. Consequently, three types of upper limb voluntary movement were chosen corresponding to a factor which integrates the effect of the movement to the body structure, which is referred to as dynamic asymmetry. The study of the segmental phenomena would enable a deeper understanding of the posturo-kinetic organisation related to the early phase of the intentional movement in normal subject. It could afford reference data for the assessment of motor impairments in pathological disease such as Parkinson's disease, which is the matter of the next paper.

\section{Methods}

Movements of anterior flexion of the upper limb were investigated according to three conditions: bilateral flexions, $B F$, and unilateral flexions with no additional inertia, OUF, and with an additional inertia, IUF (the inertia was constituted by a lead bracelet weighing one kilogram and fastened to the distal part of the forearm). These three types of movement correspond to a dynamic asymmetry increasing from BF to IUF.

Activity of the right anterior portion of deltoid (DA), prime mover of the voluntary movement, and activities of the main muscles of the lower limbs and pelvis and/or of trunk and scapular girdle were recorded on ipsilateral (i) and contralateral (c) side by surface electromyography (band width: 3-700 Hz). The muscles were, for the lower limbs and pelvis: the gluteus maximus (GM), the tensor fasciae latae (TFL), the semi-tendinosus (ST), the rectus femoris (RF), the vastus lateralis (VL), the tibialis anterior (TA) and the soleus (SOL), and for the trunk and scapular girdle: the sternal portion of the pectoralis major (PMS), the trapezius superior (TS), the serratus anterior (SA), the rectus abdominis (RA), the obliquus externus (OL), the latissimus dorsi (LD) and the erectores spinae (ES).
Miniature mono-axial accelerometers (ENTRAN piezoelectric gauge, EGCS standard type) fixed on appropriately shaped splints were bound to the wrist of the moving upper limb and to various body segments. This made it possible to measure the tangential acceleration of the arm $\left(\mathrm{Aw}_{\mathrm{i}}\right.$, linearity range: $\pm 10 \mathrm{~g}$ ) and to determine the onset, the sign and the amplitude of the early antero-posterior accelerations (linearity range: $\pm 2 g$ ) at trunk level (Atr) and at ipsilateral (i) and contralateral (c) shank (As), thigh (At), hip (Ah) and shoulder (Ash) levels.

Subjects stood in a "natural" position, with their feet normally spread out; their arms were freely hanging along the body. A contact closing a delay line circuit was held in place by their right hand. The instructions given to the subjects were to point out, with their upper limb(s) stretched out, at target(s) located in front of them at shoulder level and at a distance just out of reach of their upper limb(s). The task was to perform movement at maximum velocity, the subjects being free to choose the instant of the movement onset.

EMG raw data were stored on a six channels F.M tape (Enertec-Euromag) with one channel related to an eight multiplexing-demultiplexing unit (Enertec MA 1142-1233) and subsequently digitised (sampling period of $1 \mathrm{~ms}$ ) in a mini-computer (PDP 11/34) so as to provide an envelope which was displayed by a digital $\mathrm{X}-\mathrm{Y}$ plotter (Tektronix 46/62). Local accelerations were recorded on the F.M tape and were subsequently digitised in the minicomputer (sampling period $5 \mathrm{~ms}$ ) and displayed on the $\mathrm{X}-\mathrm{Y}$ plotter. EMGs and accelerations were recorded during successive sessions.

Twelve right handed adults (eight men and four women), were tested. Three of them were investigated for EMG study of lower limbs and pelvis, three others for EMG study of trunk and scapular girdle, three others for accelerometric study and at least three participated in the three types of investigations. Thus six subjects were considered for each sequence. During investigations DA activity and Aw were systematically recorded. During each session subjects performed 10 movements according to each of the three types, in two series of five trials. A series of left hand movements, without and with an additional inertia were executed as control, as well as a series of passive movements.

\section{Results}

\section{EMG activities}

Modifications of EMG activity related to upper limb elevation were observed in many muscles for each subject and for each experimental condition. These postural EMG variations were phasic. Some of them did not only occur during the voluntary movement but also began before the onset of the activation of the DA, prime mover of the voluntary movement (in the case of passive upper limb elevation, no EMG modification occurred before the onset of the arm elevation). In the present paper, the EMG variations which preceded and/or accompanied the first burst of the DA activity were the only ones considered. A remarkable reproducibility of the early postural EMG activities was observed for each condition. This reproducibility occurred in a given subject and from one subject to another. (The EMG pattern changed 
from unilateral to bilateral conditions). It was interesting to note that during left upper limb movement the whole EMG pattern was symmetrically reversed with reference to the sagittal plane.

EMG activities at lower limb and hip levels (fig 1, A) For OUF condition, all the recorded muscles showed phasic variations. The most remarkable results concerned the SOLs and the muscles which cross the hip joint: TFLs GMs and Sts. EMG activities of homonymous muscles were out of phase for activations as well as for disactivations. As it has been stated above, some of these EMG variations began before the onset of the active DA(s). The most systematic anticipatory EMG variations corresponded to a decrease of the tonic postural activity of the SOL $\mathrm{L}_{\mathrm{i}}$ and to an increase in the contralateral TFL and GM and in the ipsilateral GM and ST as well. Other muscles, as the $V_{i}$, the $T A_{i}$ and the $R F_{i}$, showed occasional anticipatory activity.

In the IUF conditions, the same general pattern was observed, but the features were more accentuated. The amplitude of EMG was greater. The temporal shift between the burst of activity of the homonymous muscles, as it was described for the GMs, the TFLs and the STs was increased. The durations of the anticipatory component of the postural EMG activities (in reference to the onset of the $\mathrm{DA}_{\mathrm{i}}$ activation) increased significantly (table 1) from the OUF to IUF condition. Furthermore, the anticipatory activities occasionally recorded during the OUF movements $\left(\mathrm{VL}_{\mathrm{i}}\right.$, $\mathrm{TA}_{\mathrm{i}}$ and $\mathrm{RF}_{\mathrm{i}}$ ) appeared to be more systematic during the IUF movements.

In the BF condition, the postural pattern appeared to be different from that in the unilateral condition. Homonymous muscles showed a similar activity. This EMG activity corresponded to the one which was observed for the ipsilateral side during the unilateral movements (except for the TAs which showed an opposite tendency). In particular, there was simultaneous anticipatory relaxation of SOLs and activation of GMs and STs and VLs. Moreover, the activities of the RFs and the TFLs tended to be less intense and more tonic; they started no earlier than the onset of the DA activity. The durations of the anticipatory component of postural EMG activities decreased significantly (table 1) from the OUF to the BF condition.

\section{EMG activities at trunk and scapular girdle levels}

(fig $1, B$ )

For OUF condition, some of the muscles showed phasic activity either synchronised $\left(\mathrm{TS}_{\mathrm{i}}, \mathrm{SA}_{\mathrm{i}}\right.$ and $\left.\mathrm{LD}_{\mathrm{c}}\right)$ or shifted in time $\left(R_{A_{i}}\right.$ and $\left.L D_{i}\right)$ with the $D A_{i}$ activity. The other muscles $\left(\mathrm{TS}_{\mathrm{c}}, \mathrm{SA}_{\mathrm{c}}, \mathrm{RA}_{\mathrm{c}}\right.$ and both OEs) showed a tonic but generally weak activity during the $\mathbf{D A}_{\mathbf{i}}$ one. Two muscles showed a particular activity:

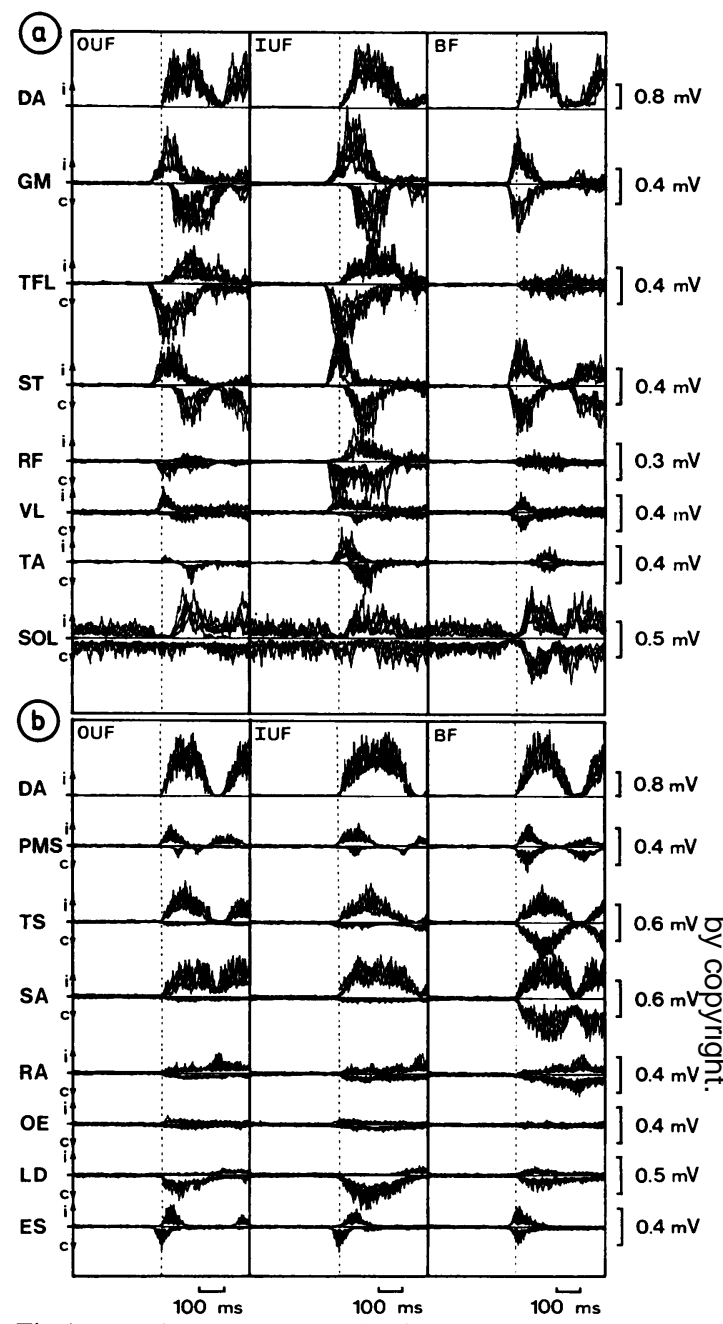

Fig 1 EMG activities recorded for the three experimental conditions. A: activities from lower limbs and pelvis muscles. From top to bottom: DA, anterior portion of deltoideus; $G M$, gluteus maximus; $T F L$, tensor faciae latae; $S T$, semitendinosus; $R F$, rectus femoris; $V L$, vastus lateralis; $T A$, tibialis anterior; SOL, soleus. B: activities from trunk and scapular girdle muscles. From top to bottom: DA, anterior portion of deltoidus; PMS, sternal portion of pectoralis major; TS, trapezoidus superior; $S A$, serratus anterior; $R A$ rectus abdominis; $O E$, oblique externus; $L D$, latissimus dorsi; ES, erectores spinae. EMG activities are reported from one subject performing the three types of movement (OUF: unilateral flexions with no additional inertia; IUF. unilateral flexions with an additional inertia; BF: bilateral flexion). For each type of movement rectified and smooth EMG activities of five trials were superimposed by synchronising records on the onset of DA activity (dotted line). Ipsilateral ( $i$ ) and contralateral (c) activities with respect to the moving limb are displayed in opposite direction. 
Table 1 Mean anticipations of systematically anticipatory EMG activities

\begin{tabular}{|c|c|c|c|c|c|c|c|c|c|c|}
\hline \multirow[b]{3}{*}{$\begin{array}{l}\text { ESc } \\
\text { GMi } \\
\text { TFLc } \\
\text { STi } \\
\text { RFc } \\
\text { SOLi }\end{array}$} & \multicolumn{2}{|c|}{$O U F$} & \multicolumn{2}{|l|}{$I U F$} & \multicolumn{2}{|l|}{$B F$} & \multirow{2}{*}{\multicolumn{2}{|c|}{$t(O U F / I U F)$}} & \multirow{2}{*}{\multicolumn{2}{|c|}{$t(O U F / B F)$}} \\
\hline & $\frac{\overline{\bar{m}}}{31 \cdot 5}$ & $\frac{s}{2 \cdot 9}$ & $\frac{\bar{m}}{33.4}$ & $\frac{s}{2 \cdot 8}$ & $\begin{array}{l}\overline{\bar{m}} \\
29.8 \\
28.0\end{array}$ & $\begin{array}{l}s \\
2 \cdot 2 \\
4 \cdot 5\end{array}$ & & & & \\
\hline & $\begin{array}{l}31 \cdot 5 \\
44 \cdot 2 \\
55 \cdot 5 \\
42 \cdot 7 \\
48 \cdot 8 \\
66 \cdot 0\end{array}$ & $\begin{array}{r}2.9 \\
8.6 \\
8.4 \\
6.9 \\
11 \cdot 1 \\
15.7\end{array}$ & $\begin{array}{l}33.4 \\
48.2 \\
62.0 \\
48 \cdot 2 \\
59.8 \\
69.2\end{array}$ & $\begin{array}{r}2 \cdot 8 \\
9 \cdot 0 \\
9.9 \\
7 \cdot 7 \\
10 \cdot 5 \\
17 \cdot 3\end{array}$ & $\begin{array}{l}29 \cdot 8 \\
28 \cdot 0 \\
\overline{28} \cdot 4 \\
\frac{62 \cdot 4}{}\end{array}$ & $\begin{array}{c}2 \cdot 2 \\
4 \cdot 5 \\
- \\
4 \cdot 7 \\
\overline{15} \cdot 0\end{array}$ & $\begin{array}{l}3.6 \\
1.6 \\
3.6 \\
3.1 \\
0.8 \\
2.5\end{array}$ & $\begin{array}{l}\frac{t}{t} \\
\frac{t}{t} \\
\frac{t}{t}\end{array}$ & $\begin{array}{l}1 \cdot 3 \\
5 \cdot 6 \\
\frac{7 \cdot 3}{1 \cdot 1}\end{array}$ & $\begin{array}{l}\frac{t}{t} \\
- \\
-\end{array}$ \\
\hline
\end{tabular}

Anticipations were measured by reference to the onset of the $\mathrm{DA}_{\mathrm{i}}$ activity.

Muscle symbols correspond to those of fig. 1, A.

Mean values (m) and standard deviations (s), in ms, were calculated for subjects performing ten movements according to the three experimental conditions, twelve subjects for $\mathrm{SOL}_{j}$ and $\mathrm{ST}_{\mathrm{i}}$ and six subjects for $\mathrm{ES}_{\mathrm{c}}, \mathrm{GM}_{\mathrm{i}}, \mathrm{TFL}_{\mathrm{c}}$ and $\mathrm{RF}_{\mathrm{i}}$.

OUF: unilateral flexions with no additional inertia; IUF, unilateral flexions with an additional inertia; BF, bilateral flexions.

$t(. . . /$.$) : Student's t$ test for paired data.

t: $\mathrm{p}<0.01$.

$*: 0.01<p<0.05$.

-: $\mathrm{p}>0.05$.

the $\mathrm{ES}_{\mathrm{c}}$ activity started always before the onset of $\mathrm{DA}_{\mathrm{i}}$ activity; the PMS $_{\mathrm{i}}$ activity was divided into two bursts, one synchronised with the $\mathrm{DA}_{\mathrm{i}}$ silence and the other present during the beginning of the $\mathbf{D A}_{\mathrm{i}}$ first burst, starting occasionally before it.

For the IUF condition, the same general pattern was observed, but the activities reported above as tonic (both $\mathrm{OE}, \mathrm{TS}_{\mathrm{c}}, \mathrm{SA}_{\mathrm{c}}$ and $\mathrm{RA}_{\mathrm{c}}$ ) tended to be more phasic. Some EMG activities started occasionally before the onset of the $\mathrm{DA}_{\mathrm{i}}$, such as the $\mathrm{PMS}_{\mathrm{i}}$, the TS and the $\mathrm{OE}_{\mathrm{i}}$. But, as for OUF, clear and systematic anticipatory activities concerned only $\mathrm{ES}_{\mathrm{c}}$. With reference to OUF, the duration of anticipatory component of $\mathrm{ES}_{\mathrm{c}}$ activity was not significantly modified (table 1).

For the BF condition, the activities of the sets of homonymous muscles showed simultaneous activities. For the scapular girdle muscles and both RA, these activities corresponded to those described above for the ipsilateral side. For both LD and both ES, these activities corresponded to those described above for the contralateral side. Thus, it appeared that activities of both ES started before the onset of the $\mathbf{D A}_{\mathrm{i}}$ activity. In addition, during BF movements both ES were the only muscles, among those listed in fig. 1B, which showed anticipatory activation. The duration of the anticipatory component of the ES activity was not significantly modified as compared with UF conditions (table 1).

To summarise, it appeared, despite variations which could be related to initial posture variations and/or to individual motor strategies, that: (1) the pattern of early postural muscles activities was reproducible and specific to the forthcoming voluntary movement; (2) the anticipatory EMG activations $(+)$ or disactivations $(-)$ showed a stable chronology: $\quad \operatorname{SOL}_{\mathrm{i}}(-), \quad \mathrm{TFL}_{\mathrm{c}}(+) / \mathrm{RF}_{\mathrm{c}}(+)$, $\mathrm{ST}_{\mathrm{i}}(+) / \mathrm{GM}_{\mathrm{i}}(+), \mathrm{ES}_{\mathrm{c}}(+)$ for the UF conditions and SOLs $(-)$, STs $(+) / \operatorname{GMs}(+) / \operatorname{ESs}(+)$ for the BF condition; this means that inter-individual sequences cor- respond to the mean intra-individual ones; (3) the duration of the anticipatory EMG modifications increased from BF to OUF and from OUF to IUF, that is, in relation to the dynamic asymmetry of the voluntary forthcoming movement.

\section{Local accelerations}

Acceleration of upper limb movement was associated with accelerations of lower limbs, trunk and shoulders. These postural accelerations occurred not only during the voluntary movement but also began before its onset (dated by onset of $A w_{i}$ ). In the case of passive upper limb elevation, no acceleration was recorded before the onset of $A w_{i}$.

For a given experimental condition, the postural local accelerations were reproducible in shape and sign for a given subject and from one subject to another. Moreover, these reproducible postural local accelerations were organised according to a pattern which varied with the experimental conditions (fig 2). It is interesting to note that during left upper limb movements the accelerometric pattern was symmetrically reversed with reference to the sagittal plane. In the following, local accelerations which preceded the onset of $A w_{i}$ have been primarily considered.

\section{Sign of anticipatory local accelerations}

The sign of anticipatory postural accelerations depended on the dynamic asymmetry of the voluntary movements. Indeed, for UF conditions, anticipatory accelerations recorded at the level of each set of homonymous segments were opposite in sign: on the ipsilateral side, As and At were directed backwards while $A h$ and Ash were directed forwards; on the contralateral side As and At were directed forwards while Ah and Ash were directed backwards. For UF conditions, Atr corresponded to a forward acceleration. 


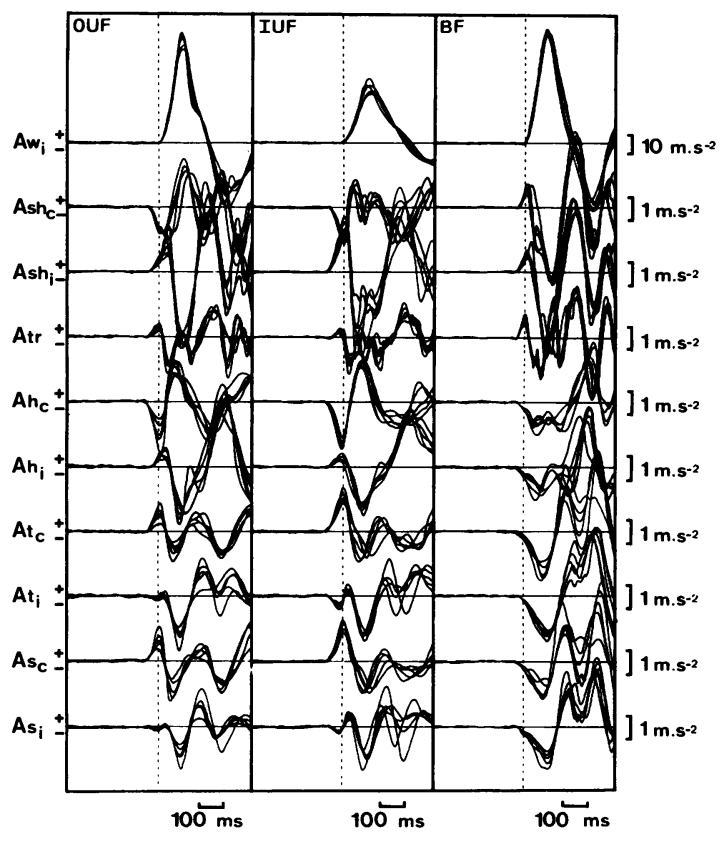

Fig 2 Local accelerations recorded for the three experimental conditions. Antero-posterior local accelerations are recorded from one subject performing the three types of movement. For each type of movement accelerations of five trials were superimposed by synchronising records on the onset of $A w_{i}$ (dotted line). From left to right: $O U F$, unilateral flexions with no additional inertia; IUF, unilateral flexions with an additional inertia; $B F$, bilateral flexions. From top to bottom: $A W_{i}$, tangential acceleration of the upper limb measured at wrist level (positive sign corresponds to the acceleration phase of the movement); Ash, Atr, Ah and As, antero-posterior accelerations measured at level of shoulders, trunk, hips, thighs and shanks (positive sign corresponds to forward accelerations); $i$ and $c$, ipsilateral and contralateral accelerations with respect to the moving limb.
For the BF condition, accelerations recorded at the level of homonymous segments had the same sign, lower limbs and hips showing backward anticipatory accelerations, and shoulders and trunk showing forward ones.

\section{Duration of anticipatory local accelerations}

The duration of the anticipatory component of local accelerations varied according to the experimental conditions (table 2). For UF conditions, local accelerations recorded on a given side started approximately at the same time. But the contralateral anticipatory accelerations started always $10 \mathrm{~ms}$ on the average before the ipsilateral ones.

For the IUF condition, the same chronometric relations were observed. But all the local accelerations started earlier than for the OUF condition. Furthermore, the delay between anticipatory contralateral and ipsilateral accelerations increased from OUF to IUF.

For BF, all the anticipatory local accelerations started at the same time. The average durations of the anticipatory component of these accelerations were shorter than for UF conditions.

\section{Amplitude of anticipatory local accelerations}

The amplitude of local accelerations at $t_{0}$ varied according to experimental conditions. Considering the differences in amplitudes between experimental conditions of anticipatory local accelerations, it was observed (table 3) that:

As and At (recorded from the two sides of the knee joint) had comparable amplitudes; for the UF conditions, amplitudes of contralateral accelerations recorded at a given level were systematically greater than ipsilateral ones; for the BF, at a given level, both anticipatory accelerations had the same amplitude; during the IUF, anticipatory local accelerations recorded at a given level showed an amplitude

Table 2 Mean anticipations of local accelerations

\begin{tabular}{|c|c|c|c|c|c|c|c|c|c|c|}
\hline \multirow{2}{*}{$\begin{array}{l}\text { Ashi } \\
\text { Ashc } \\
\text { Atr } \\
\text { Ahi } \\
\text { Ahc } \\
\text { Ati } \\
\text { Atc } \\
\text { Asi } \\
\text { Asc }\end{array}$} & \multicolumn{2}{|c|}{$O U F$} & \multicolumn{2}{|l|}{$I U F$} & \multicolumn{2}{|l|}{$B F$} & & & & \\
\hline & $\begin{array}{l}\overline{\bar{m}} \\
42 \cdot 5\end{array}$ & $\frac{s}{5 \cdot 6}$ & $\begin{array}{l}\overline{\bar{m}} \\
46.3\end{array}$ & $\frac{s}{7 \cdot 1}$ & $\frac{\bar{m}}{27 \cdot 8}$ & $\frac{s}{6.8}$ & \multicolumn{2}{|c|}{$t(O U F / I U F)$} & \multicolumn{2}{|c|}{$t(O U F / B F$} \\
\hline
\end{tabular}

Acceleration symbols correspond to those of fig. 1, B.

Anticipations were measured by reference to the onset of $A w_{i}$.

Mean values (m) and standard deviations (s), in $\mathrm{ms}$, were calculated on six subjects performing ten movements according to the three experimental conditions.

$\mathrm{t}(\ldots / \ldots)$ : Student's $\mathrm{t}$ test for paired data. 
Table 3 Differences between amplitudes of anticipatory local accelerations

\begin{tabular}{|c|c|c|c|c|c|c|c|c|c|c|c|c|}
\hline \multirow[b]{2}{*}{$A$} & \multicolumn{4}{|l|}{ OUF } & \multicolumn{4}{|l|}{ IUF } & \multicolumn{4}{|l|}{$B F$} \\
\hline & $\bar{m}$ & $s$ & $t$ & & $\bar{m}$ & $s$ & $t$ & & $\overline{\bar{m}}$ & $s$ & $t$ & \\
\hline \multirow[t]{2}{*}{$\begin{array}{l}\text { Asi-Ati } \\
\text { Asc-Atc } \\
\text { Asc-Asi } \\
\text { Atc-Ati } \\
\text { Ahc-Ahi } \\
\text { Ashc-Ashi }\end{array}$} & $\begin{array}{r}0.08 \\
-0.11 \\
0.91 \\
0.64 \\
0.64 \\
0.69\end{array}$ & $\begin{array}{l}0.005 \\
0.04 \\
0.08 \\
0.35 \\
0.35 \\
0.27\end{array}$ & $\begin{array}{c}0.02 \\
0.09 \\
14.9 \\
34 \cdot 5 \\
13.4 \\
17 \cdot 4\end{array}$ & $\begin{array}{l}- \\
\bar{t} \\
t \\
t \\
t\end{array}$ & $\begin{array}{l}0.01 \\
0.15 \\
1.34 \\
1.12 \\
0.71 \\
0.44\end{array}$ & $\begin{array}{l}0.006 \\
0.09 \\
0.21 \\
0.31 \\
0.12 \\
0.18\end{array}$ & $\begin{array}{l}0.01 \\
0 \cdot 15 \\
21 \cdot 2 \\
16 \cdot 8 \\
24 \cdot 5 \\
18 \cdot 4\end{array}$ & $\begin{array}{l}- \\
\bar{t} \\
t \\
t \\
t\end{array}$ & $\begin{array}{l}0.003 \\
0.004 \\
0.003 \\
0.002 \\
0.010 \\
0.012\end{array}$ & $\begin{array}{l}0.003 \\
0.003 \\
0.006 \\
0.004 \\
0.008 \\
0.006\end{array}$ & $\begin{array}{l}0.05 \\
0.02 \\
0.01 \\
0.03 \\
0.02 \\
0.03\end{array}$ & $\begin{array}{l}- \\
- \\
- \\
-\end{array}$ \\
\hline & \multicolumn{4}{|c|}{$(I U F-O U F)$} & \multicolumn{4}{|c|}{$(O U F-B F)$} & & & & \\
\hline$B$ & $\bar{m}$ & $s$ & $t$ & & $\bar{m}$ & $s$ & $t$ & & & & & \\
\hline $\begin{array}{l}\text { Ashi } \\
\text { Ashc } \\
\text { Atr } \\
\text { Ahi } \\
\text { Ahc } \\
\text { Ati } \\
\text { Atc } \\
\text { Asi } \\
\text { Asc }\end{array}$ & $\begin{array}{l}0.06 \\
0.27 \\
0.09 \\
0.18 \\
0.34 \\
0.06 \\
0.34 \\
0.06 \\
0.27\end{array}$ & $\begin{array}{l}0.02 \\
0.11 \\
0.05 \\
0.10 \\
0.13 \\
0.03 \\
0.11 \\
0.02 \\
0.11\end{array}$ & $\begin{array}{l}5 \cdot 6 \\
5 \cdot 6 \\
2 \cdot 2 \\
4 \cdot 2 \\
4 \cdot 3 \\
3 \cdot 8 \\
5 \cdot 0 \\
6 \cdot 3 \\
5 \cdot 2\end{array}$ & $\begin{array}{l}t \\
t \\
t \\
t \\
+ \\
+ \\
+ \\
+\end{array}$ & $\begin{array}{r}0.08 \\
0.05 \\
-0.10 \\
0.08 \\
0.50 \\
0.02 \\
0.42 \\
0.03 \\
0.45\end{array}$ & $\begin{array}{l}0.03 \\
0.04 \\
0.05 \\
0.06 \\
0.21 \\
0.02 \\
0.18 \\
0.04 \\
0.22\end{array}$ & $\begin{array}{l}3.5 \\
3.9 \\
3.8 \\
7.9 \\
5.1 \\
0.0 \\
6.3 \\
0.0 \\
6.3\end{array}$ & $\begin{array}{l}* \\
* \\
+ \\
+ \\
\frac{t}{t} \\
\frac{t}{t}\end{array}$ & & & & \\
\hline
\end{tabular}

Acceleration symbols correspond to those of fig. 1, B.

Amplitudes of anticipatory accelerations were measured at the instant of the onset of $\mathbf{A w}_{\mathrm{i}}$.

Mean values $(\mathrm{m})$ and standard deviations $(\mathrm{s})$, in $\mathrm{ms}^{-2}$, were calculated on six subjects performing ten movements according to the three experimental conditions.

$(\ldots / \ldots)$ : data corresponding to differences obtained between pairs of experimental conditions.

$\mathrm{t}$ : Student's $\mathrm{t}$ test for paired data.

A: differences between amplitudes of anticipatory local accelerations according to the segmental level of recording.

B: differences between amplitudes of anticipatory local accelerations according to the three experimental conditions.

significantly greater than those recorded during the OUF; during the OUF, except for Atr, anticipatory local accelerations showed amplitudes greater or equal to those recorded during the $\mathrm{BF}$; this difference was significant for $A h_{i}, A h_{c}, A t_{c}$ and $A s_{c}$ but not for $\mathrm{At}_{\mathrm{i}}$ and $\mathrm{As}_{\mathrm{i}}$.

\section{Time lag between onsets of EMG and local accelerations}

The electromechanical delay between the Da activity (primum movens of the movement) and the acceleration of the upper limb was on the average $42.2 \mathrm{~ms}$ $(\mathrm{SD}=2.9)$ for OUF and BF. It was not significantly modified in IUF condition $(\overline{\mathrm{m}}=42 \cdot 6 \mathrm{~ms} ; \mathrm{SD}=2)$. From tables 1 and 2, it appears that, for a given experimental condition, the anticipatory postural EMG activities preceded the $\mathrm{DA}_{\mathrm{i}}$ activity by a delay which was not significantly different from the delay between the anticipatory postural accelerations and the onset of $A w_{i}$. Thus, anticipatory postural EMG activities preceded the anticipatory postural accelerations by a delay similar to the delay between DA activity and Aw. Moreover, early electromyographical and accelerometric patterns varied in a similar way according to the experimental conditions. Indeed: (1) EMG and accelerometric anticipation both increased with the dynamic asymmetry of the forthcoming movement; (2) for both EMG and accel- erometric patterns the shift between ipsilateral and contralateral phenomena increased from OUF to IUF while for BF simultaneity was the rule.

\section{Discussion}

The results allow a complete segmental description of the anticipatory postural adjustments, an objectivisation of the influence of the dynamic asymmetry at the local level and make possible a discussion about the relations between the EMG activities and their kinetic consequences.

\section{ORGANISATION OF ANTICIPATORY POSTURAL ADJUSTMENTS}

Anticipatory EMG and accelerometric pattern features In agreement with Belenkii et $\mathrm{al}^{6}$ considering the OUF condition, and with preliminary results, ${ }^{2324}$ the present results confirm that EMG activities come into play prior to the prime mover activity of the voluntary movement. This anticipatory sequence is reproducible and specific to the forthcoming voluntary movement. It includes muscular disactivations and activations. In so far as only activations are considered, it can be emphasised that the first activation concerns the contralateral side (TFL and RF). This localisation of the first EMG response is different from the one described 

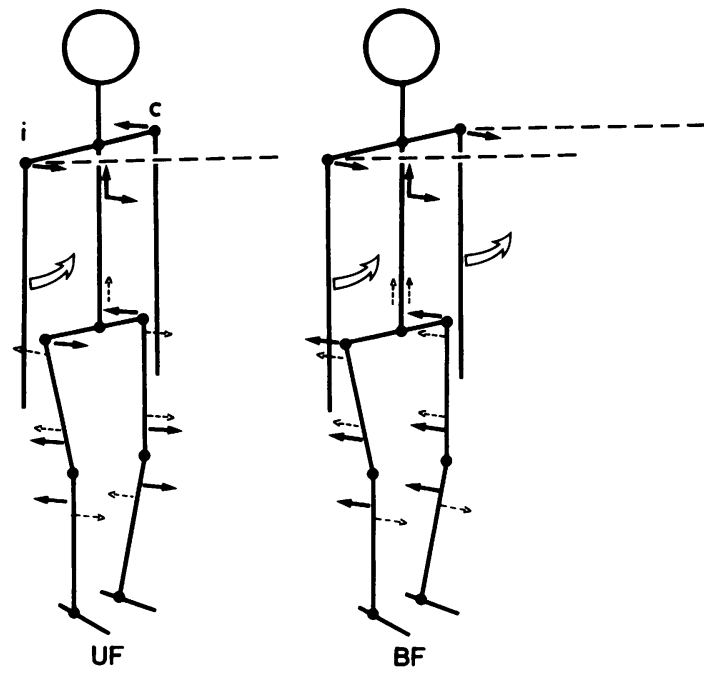

Fig 3 Scheme of muscular actions in anticipatory movements. UF: unilateral upper limb flexions (OUF and IUF); BF, bilateral upper limb flexions. $i$ and $c$ : ipsilateral and contralateral sides with respect to the moving limb for $U F$ conditions. Filled arrows correspond to anticipatory local accelerations. Dotted arrows correspond to articular action deduced from anticipatory EMG activities.

by Belenkii et al for which the first activation concerned the ipsilateral hamstrings which, according to the present data, are activated after the contralateral muscles. However, the first change which was observed in the muscular pattern was a systematic inhibition of ipsilateral soleus, already described for OUF by Gouny et $a l^{8}$ and not an inhibition of the contralateral hamstrings (in which a previous tonic activity is only occasionally present).

The sequence of EMG modifications follows a distalproximal order. However, no anticipatory activity was recorded from foot muscles in preliminary experiments. This chronology has been described in the case of postural reactions induced by perturbations of the postural basis. ${ }^{26}$ It was also reported in the case of anticipatory postural adjustments associated with voluntary elbow flexion-extension. ${ }^{3}$ The anticipation of EMG modifications increases according to the dynamical asymmetry. It concerns mainly muscles acting at knee and hip levels but not those acting at lumbar spine level, contrary to the results of Horak et $a l .^{19}$ Besides, no anticipatory muscular activity was recorded at trunk and scapular girdle level.

It is well known that the EMG signal is a convenient index of the excitation level of a muscle. However, it is difficult to infer from EMG recordings the external effect of the muscular contraction and it is necessary to relate EMG to relevant kinematic and/or kinetic quantities. Results from the accelerometric method show that there are local accelerations before the onset of voluntary movement. Thus, anticipatory postural adjustments are postural movements and do not consist in a simple rigidification of some joints. These dynamic phenomena result from phasic EMG activities.

Despite the fact that a segmental acceleration is a resultant of mechnical effect, it must be emphasised that EMG and accelerometric anticipatory patterns showed similar features. Indeed: (1) for UF conditions, ipsilateral anticipatory modifications were different from the contralateral ones, while, for $\mathrm{BF}$ condition, identity was the rule; (2) anticipation of the legs and pelvis EMG activations and of the earliest local accelerations increased with the dynamic asymmetry of the forthcoming voluntary movement. Moreover, it should be noted that low intra- or interindividual variability in EMG patterns was less discernable in the accelerometric pattern which corresponds to their peripheral expression. Thus, it appears that whatever are the anticipatory postural movements induced by anticipatory muscular activities their features are reproducible and specific to the type of forthcoming voluntary movement.

Nature of muscular action in anticipatory postural movements

The close relations between EMG and accelerometric anticipatory patterns make it possible to determine the nature of anticipatory postural movements (fig 3 ).

The earliest anticipatory EMG modification was a disactivation of ipsilateral soleus for UF and of both soleus for BF. Consequently, an extension of the ankle(s) could be expected. Now, the sign of the acceleration of the corresponding shank(s) indicate rather a flexion of the ankle. Thus, it should be considered that anticipatory movement of shank results from activity of muscles acting on distant joint(s) and that the mechanical effect of soleus disactivation might be masked because of the inertial effects of the subjacent body parts.

Movement of knees and hips can be explained by comparing data from BF with those from UF. Indeed, for BF, early acceleration of knees and hips were simultaneous and directed backwards. Thus, an extension of both knees and hips could be supposed. Anticipatory activation of pairs of ST and GM might be considered as responsible for hip movement while knee flexor action of ST might be supposed to be compensated by the weak VL activation. For UF, ipsilateral anticipatory EMG activations corresponded to those recorded on both sides for BF; thus 
it might be expected that they have a similar action. This is in agreement with the sign of ipsilateral shank and thigh accelerations but not with the sign of ipsilateral hip acceleration. On the contralateral side, anticipatory EMG activations concerned TFL and RF, that is to say muscles acting on knee and hip with an opposite action with reference to the muscles active on the ipsilateral side. Thus it might be expected that these muscles induce a hip extension associated with a knee flexion; this was again in agreement with the sign of shank and thigh accelerations but not with the sign of hip acceleration. Thus, for UF there is a contradiction between the sign of hip acceleration which is recorded and that which is deduced from joint action when considering EMG activities. Nevertheless, this contradiction can be eliminated by considering on the one hand, that opposite movements of knees induce a rotation of the pelvis about a vertical axis from the ipsilateral side to the contralateral one, and, on the other hand, the opposite action of the muscles on the two sides of the pelvis cannot induce opposite rotations of these two sides according to a transversal axis.

At trunk level, only ES has been found consistently active before DA. For BF, bilateral ES activation might induce an extension of the spine. This movement should induce an upward acceleration: this was confirmed at shoulder level by complementary records and at the body's centre of gravity level using a force platform. ${ }^{23} 25$ In so far as the upward movement of the trunk should be associated with a forward movement the recorded forward shoulder accelerations could be explained; nevertheless, passive reaction of the trunk to the pelvis movement could not be excluded.

For UF, unilateral anticipatory activation of $\mathrm{ES}_{\mathrm{c}}$ suggest an anticipatory rotation of the trunk from the ipsilateral side of the contralateral one. This rotation is in agreement with the sign of the accelerations recorded at shoulder level. However, the actions of the trunk muscles occasionally acting earlier, in particular for IUF, are in agreement with the above rotation of the trunk. Nevertheless, anticipation of shoulder accelerations is sensitive to the dynamic asymmetry of the movement while anticipation of ES activity is not; thus, trunk and shoulder movements appear to be rather a consequence of pelvics movements.

In conclusion, early postural movements cannot be directly deduced only from the theoretical joint actions of the recorded muscles. They might result from muscular actions at the joint under consideration and passive forces resulting from muscular activities acting on distant joints: there is energy transfer from forces resulting from muscular action at distant joints which are transformed through the body. ${ }^{25}$
CONTROL OF ANTICIPATORY POSTURAL ADJUSTMENTS

\section{Programming of anticipatory postural adjustments ( $A P A)$}

It has been shown that anticipatory postural movements are reproducible for one subject and from one subject to another for a given experimental condition and are specific to the type of forthcoming movement. Thus, APA should be considered as preprogrammed in so far as they depend on the same parameters as the voluntary movement which they precede. These data suggest the hypothesis according to which voluntary movement and its associated APA are parts of the same motor program. This hypothesis is compatible with the model proposed by Gahery and Massion ${ }^{27}$ according to which the central motor command triggers both the voluntary movement and the postural adjustments which are necessary to secure its postural basis.

Recent data ${ }^{28}$ confirm this theory. They prove that dynamic asymmetry is a preprogrammed movement parameter. Indeed, when studying the effect of dynamic asymmetry in a simple reaction time paradigm, results indicate that the reaction time (RT) varied from one condition to another. But if RT was divided into two parts, motor latency (ML) and postural anticipation (PA), it could be seen that ML was constant whereas PA varied. More precisely, PA increased with the dynamic asymmetry and this was, in fact, not surprising because it corresponds to the APA, presented above. Therefore, ML was equivalent to the "true RT" in that type of motor activity. Thus this emphasises that PA is a part of the motor program.

\section{Initiation of anticipatory postural adjustments}

If it is assumed that voluntary movement and its associated postural adjustments are part of a same motor program, the question may be raised concerning nervous control organisation of anticipatory postural activities. Two hypotheses may be considered: anticipatory activities may correspond to sequences of spinal reflexes and/or they may result from triggering of functional muscular synergies.

According to the first hypothesis, it should be noted that the sequence of anticipatory EMG modifications recorded in the present experiments are consistent with the results of Pierrot-Deseilligny et al. ${ }^{29}$ These authors have shown that group I afferents from ankle muscles modulate knee muscle activities: I afferents from soleus are strongly excititatory on ipsilateral quadriceps and lightly inhibiting on ipsilateral hamstrings, while I afferents from anterior tibialis are inhibiting on ipsilateral quadriceps and lightly excititatory on ipsilateral hamstrings. In the present 
experiment, the sequence of anticipatory activations of knee and pelvis muscles could be related to soleus silence(s) according to the data of Pierrot-Deseilligny et al. Therefore, anticipatory postural activities should be organised from a central command which triggers soleus silence(s). This should induce a sequence of spinal reflexes which induces, as a result, the appropriate postural EMG sequence: $\mathrm{ST}_{\mathbf{i}} / \mathbf{G M}_{\mathrm{i}}$ and $T F L_{c} / R_{c}$ for UF, both GM/ST for BF. But, the delay between soleus silence and onset of other anticipatory postural muscles appears to be too short to be in accordance with a reflex loop. Furthermore, in the case of UF, the earliest anticipatory postural activities are contralateral, which is not in accordance with possible cross reflexes.

The second hypothesis can be examined in relation to the theory proposed by Nashner ${ }^{30}$ who studied the organisation of the muscular synergies following perturbations of the postural basis constituted by various combinations of sway component (rotations about the transversal axis of each ankle) and suspension component (vertical translation of each foot support). According to this author, the muscular synergies following different combinations of these two disturbing components are centrally programmed from visuovestibular and proprioceptive inputs, which inform the CNS about the relative importance of each component.

It is tempting to consider here that postural pertubation associated with voluntary movement might result from the arrangement of two factors which may be defined from a biochemical standpoint: a linear factor and a rotational one. The linear factor might be related to anticipatory EMG activities and local accelerations of ipsilateral side for UF, and of both sides for BF in which the linear factor was the only one implicated. In such a way, the rotational factor might be related to the shift between the pairs of homonymous muscles associated with the coming into play of the contralateral antagonists, recorded for UF in which the anticipatory rotation of the trunk was implicated. Thus, it can be assumed that posturokinetic command might trigger the adequate functional muscular synergies from a previous evaluation of the relative importance of these two disturbing factors.

\section{Biomechanical finality of anticipatory postural adjustments}

In studying the finality of APA, it seems necessary to consider the forces of reaction acting on the body at the beginning of the arm movement. The upper limb movements studied are supposed to be executed in a parasagittal plane and consequently the forces of reaction applied at shoulder level act, for the three experimental conditions, backwards and downwards.
Furthermore, for UF conditions, the antero-posterior component of the perturbation induces a rotation about a vertical axis directed towards the ipsilateral side, with a greater amplitude for IUF than for OUF.

Now, before the onset of the movement, anticipatory shoulder accelerations were recorded which are directed forward for BF, and which evoke a rotation about a vertical axis directed towards the ipsilateral side for UF conditions. Thus, it appears that biomechanical effects of anticipatory postural adjustments are specifically opposite in sign, at trunk level, to biomechanical effects of perturbation associated with the forthcoming movement. These findings based on partitive accelerometry are confirmed by experiments using a force platform. ${ }^{25}$ They show that at the level of the body's centre of gravity an anticipatory resultant force directed forwards and upwards can be recorded, associated in UF conditions, with an anticipatory resultant moment directed toward the ipsilateral side.

\section{References}

1 Babinski J. L'asynergie cérébelleuse. Revue de Neurologie 1899;7: 806-16.

2 Basmajian JV, De Luca CG. Muscles Alive. Baltimore: Williams and Wilkins Pubs. 1985:561.

3 Hess WR. Teleokineiisches und ereismatisches kräftesystem in der biomotorik. Helvetica Physiology Pharmacology Acta 1943;1:C62-C63.

4 Bernstein N. Coordination and Regulation of Movements. NewYork: Pergamon Press, 1935 (translation 1967).

5 Gelfand IM, Gurfinkel VS, Tsetlin ML, Shik ML. Problems in analysis of movements. In: Gelfand IM, Gurfinkel VS, Fomin SV, Tsetlin ML, eds. Models of the Structural Functional: Organization of Certain Biological Systems. Cambridge: MIT Press, 1966 (translation, 1971):330-345.

6 Belenkii YY, Gurfinkel V, Paltsev YI. Element of control of voluntary movements. Biofizika 1967;12:135-41.

7 Verriest JP. Perturbations affectant l'équilibre général du corps liées à l'exécution d'un mouvement simple de l'avant-bras. Essais d'évaluation globale à l'aide d'une plateforme de forces. Thèse de 3e Cycle. Lille: 1972:115.

8 Gouny $\mathrm{M}$, Brenière $\mathrm{Y}$, Do MC, Lestienne F. Modalité d'intervention de la vision sur les réactions posturales liées à la mobilisation volontaire du bras. C.R. Académie des Sciences, Paris 1977;285;série D:1115-8.

9 Marsden CD, Merton PA, Morton HB. Anticipatory postural responses in the human subject. $J$ Physiol (Lond) 1978;275: 47-48.

10 Lee WA. Anticipatory control of postural and task muscles during rapid arm flexion. J Motor Behavior 1980;12:185-96.

11 Cordo PJ, Nashner LM. Properties of postural movements related to a voluntary movement. $J$ Neurophysiology 1982;47:287-303.

12 Hugon M, Massion J, Wiesendanger M. Anticipatory postural changes induced by active unloading and comparison with passive unloading in Man. Eur J Physiol 1982;393:292-6.

13 Friedli WG, Hallett M, Simon SR. Postural adjustments associated with rapid voluntary arm movements; 1. Electromyographic data. J Neurol Neurosurg Psychiatry 1984;47: 611-22.

14 Gahery Y, Nieoullon A. Postural and kinetic coordination following cortical stimuli which induce flexion movements in the cat's limbs. Brain Res 1978;155:25-37. 
15 Ioffe ME, Andreyev AE. Inter extremities coordination in local motor conditioned reactions of dogs. Zh Vyssh Nerv Deyat 1969;19:557-605.

16 Dufosse M, Macpherson J, Massion J. Biomechanical and electromyographical comparison of two postural supporting mechanisms in the Cat. Exp Brain Res 1982;45:38-44.

17 Paltsev YI, Elner AM. Preparatory and compensatory period during voluntary movement in patients with involvement of the brain of different localization. Biofizika 1967;12:161-8.

18 Traub MM, Rothwell JC, Marsden CD. Anticipatory postural reflexes in Parkinson's disease and other akinetic-rigid syndromes and in cerebellar ataxia. Brain 1980;103:393-412.

19 Horak FB, Esselman P, Anderson ME, Lynch MK. The effect of movement velocity, mass displacement, and task certainty on associated postural adjustments made by normal and hemiplegic individuals. J Neurol Neurosurg Psychiatry 1984;47: $1020-8$.

20 Dick JPR, Rothwell JC, Berardelli A, et al. Associated postural responses in Parkinson's disease. $J$ Neurol Neurosurg Psychiatry 1986;49:1378-85.

21 Regis H, Trouche E, Massion J. Effet de l'ablation du cortex moteur ou du cervelet sur la coordination posturo-cinétique chez le chat. Electroencephalogr Clin Neurophysiol 1976;41:348-56.

22 Nieoullon A, Gahery Y. Influence of pyramidotomy on limb flexion movements induced by cortical stimulation and associated postural adjustment in cat. Brain Res 1978;155:39-52.

23 Bouisset S, Zattara M. A sequence of postural movements precedes voluntary movement. Neurosci Lett 1981;22:263-70.

24 Bouisset S, Zattara M. Anticipatory postural movements related to a voluntary movement. International Conference on Space Physiology (C.N.E.S.), Cepadues Eds. Toulouse: Space Physiology, 1983:137-141.

25 Bouisset S, Zattara M. Biomechanical study of the programming of anticipatory postural adjustments associated with voluntary movement. J Biomech 1987;20:735-42.

26 Horak FB, Nashner LM. Central programming of postural movements: adaptation to altered support-surface configurations. J Neurophysiol 1986;55:1369-81.

27 Gahery Y, Massion J. Coordination between posture and movement. Trends in Neuroscience 1981;81:199-202.

28 Zattara M, Bouisset S. Chronometric analysis of posturo-kinetic programming of voluntary movement. J Motor Behavior 1986;18:215-23.

29 Pierrot-Deseilligny E, Bergero C, Katz R, Morin C. Pattern of group I fibre projections from ankle flexor and extensor muscles in man. Exp Brain Res 1981;42:337-50.

30 Nashner LM. Organization and programming of motor activity during posture control in reflex control of posture and movement. Prog Brain Res 1980;50:177-84. 